\title{
Meio ambiente e saúde - Análise à luz do pensamento sistêmico
}

\section{Environment and health - Analysis in the light of systemic thinking}

DOI: $10.46919 / \operatorname{archv2n2-006~}$

Recebimento dos originais: 01/01/2021

Aceitação para publicação: 31/03/2021

\section{Adelcio Machado dos Santos}

Doutor em Engenharia e Gestão do Conhecimento pela Universidade Federal de Santa Catarina (UFSC). Pós-Doutor em Gestão do Conhecimento pela UFSC. Universidade Alto Vale do Rio do Peixe (UNIARP). Endereço: Rua Victor Baptista Adami, 800 - Centro - Caçador/SC/Brasil. CEP 89500-199.

E-mail: adelciomachado@gmail.com

\section{Rubens Luís Freiberger}

Mestrando do Programa de Mestrado Acadêmico em Desenvolvimento e Sociedade da UNIARP, Caçador/SC/Brasil.

E-mail: rubens.freiberger@gmail.com

\section{Dreone Mendes}

Mestrando do Programa de Mestrado Acadêmico em Desenvolvimento e Sociedade da UNIARP, Caçador/SC/Brasil.

E-mail: rubens.freiberger@gmail.com

\section{RESUMO}

Aspectos primordiais relacionados com o desenvolvimento e o meio ambiente, como população, saúde, paz, direitos humanos, democracia, fome, degradação da flora e da fauna, devem ser abordados dessa maneira. $\mathrm{O}$ conceito de ambientalismo multissetorial surge indicando o posicionamento ao mesmo tempo de ordem teórica e política, relacionado a visões alternativas do ambientalismo, como por exemplo, a que considera este movimento mais um grupo de interesse. A ampla difusão da preocupação com a qualidade do meio ambiente tanto em países de alta renda quanto nos países de baixa renda coloca em xeque a crença de que a preocupação com a qualidade ambiental é mais comum nas sociedades afluentes. A explicação deste fato reside na mudança da percepção em relação à temática ambiental-saúde que, principalmente nos países de baixa renda, estaria sendo vista mais como questão de sobrevivência do que uma questão de ordem estética. A conexão meio-ambiente-saúde aparece com um dos aspectos mais marcantes do ambientalismo como fenômeno social, que deve ser analisado à luz do Pensamento Sistêmico.

Palavras-chave: Meio ambiente. Saúde. Pensamento Sistêmico.

\begin{abstract}
Primary aspects related to development and the environment, such as population, health, peace, human rights, democracy, hunger, degradation of flora and fauna, must be addressed in this way. The concept of multisectoral environmentalism appears indicating the positioning at the same time of a theoretical and political order, related to alternative views of environmentalism, such as, for example, the one that considers this movement more of an interest group. The widespread concern about the quality of the environment in both high-income and low-income countries calls into question the belief that concern for environmental quality is more common in affluent societies. The explanation for this fact lies in the change in perception in relation to the environmental-health theme, which, especially in low-income countries, would be seen more as a question of survival than as a question of an aesthetic order. The environment-health connection
\end{abstract}


appears with one of the most striking aspects of environmentalism as a social phenomenon, which must be analyzed in the light of Systemic Thinking.

Key-words: Environment. Health. Systemic Thinking.

\section{INTRODUÇÃO}

A relação entre o meio ambiente e a saúde estreitam seus laços quando se constata de que, em curto período, a questão ambiental vem sendo absorvida pelos mais diversos setores da sociedade (LIMA, 1999).

Destarte, verificam-se duas abordagens sobre o meio ambiente como um problema social, a primeira defende que a preocupação e a mobilização social em torno da proteção ambiental surgem como reações esperadas, consequentes das condições atuais da degradação do meio ambiente e das variáveis que interferem nas mesmas. Dessarte, não existe separação entre os pressupostos básicos do cientista social, de parcelas de cientistas naturais e do ativista ambientalista. A segunda perspectiva fundamenta-se na proposta de reformulação da sociologia dos problemas sociais, deslocando o foco de atenção das condições objetivas para o processo social de construção do meio ambiente como problema social (LIMA, 1999; BARCIOTTE, SACARO JUNIOR, 2012).

No mundo moderno, cada vez mais se observa a necessidade de novas maneiras de ensinar, pensar e agir. Com as modificações tecnológicas, faz-se necessário um sistema educacional que primeiro e primordialmente faça com que a ciência chegue ao menos favorecidos, é necessária a compreensão de disciplinas tais como: física, química, matemática e biologia.

Assim será possível, entre outros aspectos, utilizar sistematicamente as informações adquiridas e processadas a partir destes campos de conhecimento na relação entre o meio ambiente e a sociedade. Um dos obstáculos encontrados para se colocar em prática inovações e novas ideias é que os indivíduos tendem a confiar em suas antigas e testadas maneiras de pensar e agirem empiricamente.

Há necessidade que a criatividade e a inovação sejam base para o planejamento de atividades produtivas e educativas, que influenciem a construção da sociedade em um meio ambiente de interpretação dinâmica (OLIVEIRA, 2012).

Nesse contexto, o universo social e organizacional se assemelha ao universo, tal como é conhecido, tanto na forma estrutural como em suas dinâmicas. Existem ainda visões semelhantes, na comparação entre os dois universos, para o entendimento do nível micro e macro, considerando que tudo é um único processo que se encontra em constante movimento e mudança, em contextos extremamente interdependentes e complementares (SILVA, 2019).

O Pensamento Sistêmico pode ser entendido como a capacidade de perceber, modelar e avaliar as consequências das ações de maneira expandida no tempo e no espaço (OLIVEIRA, 2012). Podendo ser tido 
também, como a forma de pensar e construir o pensamento, no sentido cognitivo, em que o processamento deste conhecimento é influenciado por uma linguagem de base sistêmica.

Numa compreensão integrada desse universo social e organizacional, o Pensamento Sistêmico apresenta-se como possibilidade promissora, visto que procura entender essas visões macro e micro, segundo um todo maior do que a soma das compreensões segmentadas, compreensões estas que ainda predominam nos estudos sobre tal universo (SILVA, 2019).

Alternativas de compreensão das organizações constituem-se particular desafiador entre os estudos organizacionais, embora as organizações existam, não existem compreensões suficientemente consistentes que unam o macro ao micro universo organizacional (SILVA, 2019).

Conforme Santos et al. (2007) na década de 60, Peter Senge apresentou as abordagens referentes à Quinta Disciplina, que servem como embasamento para o Pensamento Sistêmico. Algumas transformações ocorridas com a educação nos últimos tempos influenciam e modificam o pensar e fazer educação.

A partir do Pensamento Sistêmico embasado nas ideias de Senge busca-se incrementar as metodologias sistemáticas de ensino, como será apresentado. Até porque a abordagem sistêmica caminha lidar com a complexidade dos sistemas, o realismo dos modelos, e a resolutividade dos problemas.

À medida que o sistema é simplificado, perde o realismo, mas se torna de maior resolutividade. Em contraposição, na medida em que se aumenta o realismo do modelo proposto, mais complexo se torna o sistema e de mais difícil resolução (SILVA, 2019).

A partir de todo o panorama apresentado e colocado em prática, ainda é possível inferir uma lacuna entre a ação e a teoria, que aos poucos vem sendo preenchidas pelas Ciências Sociais, com apresentação de alguns conceitos, como o da neutralidade total do cientista e nesse contexto as diferentes metodologias sistêmicas exercem papel fundamental.

\section{DESENVOLVIMENTO}

A definição de um problema emerge dentro de determinado cenário cultural e de organização das instituições públicas, a princípio se reconhece que todas as demandas são importantes, entretanto a dinâmica social e política confere destaque aos atributos e aos problemas que são considerados condições sociais problemáticas à população. Juntamente com o contexto cultural, elementos estruturais, no Brasil a organização do Estado e a Constituição Federal, também configuram o contexto do processo de definição dos assuntos públicos e que merecem atenção social (BRASIL, 1988; FUKS, 2000).

A disputa em torno da definição dos problemas sociais possui uma dimensão na herança histórica local/contextual, responsável pela geração do repertório de recursos culturais disponíveis (SHIKI, 2004; CUNHA; AUGUSTIM, 2014). Os recursos simbólicos contidos nas leis são abstratos demais para definir o sentido do meio ambiente. Eles apenas estabelecem conflitos gerais. 
No sentido do meio ambiente, como problema social não é gerado exclusivamente por categorias que o definem, também depende da configuração dos contornos do problema ambiental no âmbito das disputas locais. Exaustivamente os problemas relacionados ao meio ambiente são exemplificados quanto à disputa de terras, questões imobiliárias, ameaça na destruição de moradias populares, como núcleo do problema ambiental da cidade e que exigem uma solução da justiça (FUKS, 2000).

Por conseguinte, observa-se que ocorre um avanço quanto à preocupação do meio ambiente, sendo exaustivamente discutido, em função da degradação da natureza e consequente decadência da qualidade de vida, tanto nas cidades quanto no campo. Entre outras razões, esta situação decorre do mau gerenciamento ambiental advindo do setor público e privado. O desenvolvimento social abrange outras dimensões além da ecológica, implicando em última análise na melhor qualidade de vida.

O valor econômico ou o custo de oportunidades dos recursos ambientais, muitas vezes não é observado no mercado por intermédio do sistema de preços. Desse modo Motta (2006) destaca que, no entanto, como os demais bens e serviços presentes no mercado, seu valor econômico deriva de seus atributos, com a peculiaridade de que estes atributos podem ou não estar associados ao uso. Os usos e nãousos dos recursos ambientais encerram valores que precisam ser mensurados para se fazerem opções entre usos e não-usos diversos e até mesmo conflitantes, ou seja, quando um tipo de uso ou de não-uso exclui, necessariamente, outro tipo de uso ou não-uso. Como exemplo, Motta (2006) cita que o uso da Baía de Guanabara localizada na cidade do Rio de Janeiro, para diluição de esgoto exclui (ou pelo menos limita) seu uso para recreação.

A questão ambiental surgiu de maneira explosiva há aproximadamente três décadas, até então, somente os aspectos sanitários do problema eram abordados, especialmente aqueles que estavam relacionados inteiramente à poluição da água e aos consequentes episódios de mortandade de peixes, à poluição do ar e às perturbações das doenças dela advindas (SILVA, 2010). De acordo com Branco (2004), o próprio termo preservacionismo aplicava-se tão-somente à proteção contra a erosão do solo.

A preservação e manutenção das condições naturais do meio ambiente constituem-se como condição indispensável para a qualidade de vida das gerações futuras, bem como para a sua própria permanência no planeta (PELEGRINI, 2006). A destruição do meio ambiente, por meio de impactos constantes, pode tornar inviável a preservação da vida dos seres humanos. Sendo assim, é essencial que todas as atividades realizadas por meio da ação humana sejam empreendidas de tal forma que possam ser ambientalmente sustentáveis.

Nos dias atuais, a questão ambiental, além de ser do interesse dos cientistas e dos ecologistas, também vem sendo analisada pela sociedade em geral. A questão ambiental está se tornando um assunto obrigatório nas salas de aula, nas discussões de políticas regionais, nacionais e internacionais, nas agendas dos executivos, tal fato está acontecendo em decorrência de um relacionamento entre o meio ambiente e o 
desenvolvimento econômico, que acabou por modificar o ponto crítico para os negócios. O princípio de sustentabilidade do novo paradigma é elemento-chave pra todas as versões do pensamento ambientalista e não apenas no campo econômico, sendo assim, os métodos propostos para verificar o grau de sustentabilidade dos sistemas humanos constituem-se em instrumental importante para identificar a evolução de uma determinada formação social.

Para Montibeller Filho (2004) se destaca que em princípio, considerada isoladamente, uma formação social concreta pode apresentar-se positivamente em relação ao desenvolvimento sustentável. Entretanto, em geral, os economistas ambientais não são explícitos em relação à questão mais relevante, pois que coerente com uma visão humanista, a saber, quando à probabilidade de se alcançar em escala planetária, no capitalismo, o novo padrão de desenvolvimento.

Nesse contexto, sustentabilidade é uma terminologia que recentemente ganhou popularidade e que, de uma maneira geral, significa a utilização de determinado recurso natural de tal forma que ele permaneça continuamente disponível. Contudo, o termo é utilizado de maneira vaga e equivocadamente em certas circunstâncias. Assim, Zilberman (1997) destaca que esse termo é definido como a garantia de que as futuras gerações terão iguais oportunidades de acesso aos recursos oferecidos atualmente pelo planeta.

Há também a argumentação, de acordo com o mesmo autor, que a sustentabilidade se refere a tipos de desenvolvimento que são economicamente viáveis, não agridem ao ambiente e são socialmente justos. Entretanto, é necessário aprender como manter os recursos ambientais, de forma a continuarem a prover benefícios à população humana e a outras formas de vida no planeta.

$\mathrm{Na}$ realidade a sustentabilidade social perdeu seu valor em detrimento de um sistema gerador de desigualdades, com a concentração fundiária nas mãos de poucos, expulsando grande parte da população para as periferias das cidades gerando miséria, pobreza, abuso de drogas lícitas e ilícitas, violência, desemprego, entre outras tantas mazelas sociais (NEY; HOFFMANN, 2009). Cabe urgentemente a formulação de um planejamento social que comtemple educação, saúde, trabalho, renda, habitação, aposentadoria as atuais e as novas gerações.

Atualmente, de acordo com as informações disponibilizadas pela Fundação Nacional da Saúde (2020) tem-se plena consciência dos danos decorrentes da má disposição de resíduos produzidos pelo homem. Tal reconhecimento, embora possibilite permanentes avanços no âmbito técnico e legal, de modo a assegurar a proteção ambiental, ainda deixa muito a desejar em termos de estabelecimento de ações práticas direcionadas a promoção da educação ambiental.

É substancial que os problemas ambientais e a crise urbana sejam avaliados de forma integrada, interdisciplinar e global, desconsiderando a existência de fronteiras políticas entre as diferentes nações (CUNHA; AUGUSTIM, 2014). Ou seja, a preservação do meio ambiente para garantir a qualidade de vida, 
é uma questão de responsabilidade mundial, que exige um trabalho em conjunto por parte dos mais diversos países.

O aumento crescente da conscientização da sociedade em benefício da preservação ambiental vem provocando pressões de entidades não governamentais e de comunidades sobre os governos e as empresas para que estas admitam a responsabilidade sobre os estragos provocados ao meio ambiente, para que assim então seja realizada uma administração voltada à consciência ecológica (CUNHA; AUGUSTIM, 2014). O número crescente de leis de proteção ambiental, grandes investimentos em pesquisas e tecnologias limpas por parte das empresas, a criação de organizações denominada Organização Não Governamental (ONGs) e a participação mais ativa da sociedade é considerado um fato mundial. Todos esses progressos ainda não são suficientes para proteger o planeta e as previsões são sombrias em relação ao meio ambiente.

Já Brügger (1998, p. 63) afirma que:

\footnotetext{
"Poluição, extinção e mau uso dos recursos naturais são, sobretudo sintomas - assim como a febre é um sintoma, e não uma doença - de uma crise maior: a crise de paradigma e de civilização".
}

O assunto é complexo e envolve fatores políticos, econômicos, sociais e até mesmo culturais entre todas as nações e por isto a decisão do problema não é tão fácil.

No Brasil, cresce a consciência ecológica e existem leis mais severas, mas ainda não existe uma ação política concretizada nessa área, apesar de ser evidente que esses modos estão modificando, ainda que de maneira bastante pausada. A educação ambiental figura na Constituição Federal de 1988 no Art. 225, inciso VI, em consonância com a qual a "promoção da Educação Ambiental em todos os níveis de ensino e a conscientização pública", como um dos deveres do poder público para garantir o direito ao meio ambiente equilibrado de forma ecológica, sendo tido como bem de uso comum do povo e essencial à qualidade de vida (BRASIL, 1988).

Para que os detrimentos ambientais não alcancem maiores proporções, isto é, estragos irreversíveis, será indispensável que todos se unam. Os problemas que circundam a realidade ambiental do país determinam que soluções imediatas sejam tomadas, ainda que sejam parciais, preliminares e incertas. A educação ambiental será diretamente imprescindível para conscientizar a sociedade e, desta maneira, conseguir uma participação mais ativa.

A adoção de uma política ambiental mais adequada com leis mais rígidas, físcalização, monitoramento ambiental apropriado e permanente, investimentos maiores em pesquisas de solução ecologicamente sustentável para os problemas ambientais e apoios fiscais as empresas, será a opção mais viável para dominar os detrimentos e impactos negativos causados ao meio ambiente. Não obstante, na educação ambiental é necessário ainda atender aos valores éticos, ou seja, respeitar os valores que fazem parte da cultura humana local. As orientações da I Conferência Intergovernamental de Educação Ambiental, 
realizada na cidade de Tbilisi, Geórgia, Ex-URSS, em 1977, determina que, ao se tratar das questões ambientais, é indispensável analisar os aspectos culturais, sociais, políticos e éticos (BILERT, 2014).

Destaque, de acordo com Grün (1996), é fundamental executar uma abordagem hermenêutica para buscar a dimensão ética e política da educação ambiental. De acordo com essa perspectiva, a concepção de educação ambiental precisa ir além do limiar epistemológico, produzindo uma abordagem ambiental por meio de uma tematização das áreas do conhecimento em um ponto de vista ético-histórico que se estenda para além do currículo. Isso se deve ao fato de que tudo o que é transmitido nas escolas influencia a maneira como os educandos compreendem as relações existentes entre cultura e o meio ambiente (GRÜN, 1996).

Portanto, ao se utilizar um enfoque global, tendo por base numa extensa perspectiva interdisciplinar, a educação ambiental designa uma realidade dentro da qual se distingue a existência de uma profunda interdependência entre o meio natural e o meio artificial. Sendo assim, de acordo com Cheney apud Grün (1996), evidencia-se que os seres humanos são socialmente edificados e os sujeitos e as comunidades são biorregionalmente construídos.

A educação ambiental, sob a base interdisciplinar, colabora para que se explique a vinculação dos atos do presente com as decorrências do futuro. Portanto, a educação ambiental precisa ser direcionada à comunidade local, despertando o interesse das pessoas para que estas tenham participação em um processo ativo, que intente buscar a solução dos problemas dentro da conjuntura das peculiaridades que caracterizam a realidade específica de uma determinada comunidade (GRÜN, 1996).

No transcorrer dos últimos anos, observa-se o aparecimento de uma nova realidade social, que se formou a partir dos avanços tecnológicos em todas as áreas do conhecimento científico. Entretanto, o desenvolvimento econômico, que propicia o aumento de riquezas para alguns, tem como consequência um efeito indesejável, sendo que ao invés de aumentar, acaba por diminuir a qualidade de vida da população.

Um dos fatores está ligado diretamente à prática do turismo. Que acontece de forma desordenada sendo que esse crescimento acelerado de modo geral, não tem aumentado à qualidade de vida da população local, uma vez que o meio ambiente não é preservado (MEDEIROS; MORAIS, 2013). Não obstante, o turismo traga consigo o desenvolvimento econômico vem acompanhado também, de ações antiambientalistas como a poluição e a ocupação desgovernada, não respeitando os limites da natureza.

A questão da preservação do meio ambiente é um fator que atua diretamente na qualidade de vida e na saúde da população. Assim, aspectos que garantam qualidade de vida, somente estarão assegurados se o progresso local permitir aos integrantes da comunidade uma vida com dignidade, com respeito às garantias ditadas pelos direitos humanos e com a preservação do meio ambiente para as gerações futuras.

Por conseguinte, emerge que a qualidade de vida, ademais de depender do respeito aos direitos humanos e a dignidade do ser humano, igualmente depende do respeito ao meio ambiente, cuja destruição resulta em consequências que atingem diretamente a vida humana. Por sua vez, o respeito ao meio ambiente 
está ligado ao desenvolvimento de políticas públicas e práticas econômicas que garantam um desenvolvimento sustentável, ou seja, a produção de tecnologias que não contribuam para a degeneração ambiental (CUNHA; AUGUSTIM, 2014).

O debate da relação entre a natureza e o homem vem sendo feito através de uma concepção dualista, onde de um lado estão os elementos a serem transformados, ou seja, a flora e a fauna, sem um contexto social, denominado de "natureza externa". De outro lado, está a chamada "natureza universal", concebida pelo homem através de suas relações sociais de produção e de toda institucionalização construída pelo mesmo, conforme destaque de Shiki (2004).

Nessa visão o desenvolvimento se faz através da sobreposição da natureza universal sobre a natureza externa. É como se diante desses dois polos, o homem, sujeito da natureza universal, estivesse constantemente buscando dominar a natureza externa, o que levaria a criação de uma unicidade.

Esta criação conceitual de natureza não permite detectar dentro da natureza universal elementos contraditórios decorrentes dessa suposta natureza, já que são formados separadamente Shiki (2004). No máximo se constata respostas da natureza externa aos atos de dominação do homem. Do mesmo modo, a educação ambiental é uma etapa constitucional no processo de conscientização em relação à saúde.

\section{CONSIDERAÇÕES FINAIS}

É certo que, a solução para grande parte dos problemas ambientais passa, basicamente, pela educação ambiental, pelas ações coletivas, pela conscientização e engajamento da população, que ao mesmo tempo é a via para encaminhar as questões de preservação da biodiversidade, dos mananciais, da ocupação territorial e de tantos outros problemas.

O binômio meio ambiente-saúde está diretamente ligado à dinâmica do crescimento populacional e a obrigação moral para com os demais seres vivos e para com as futuras gerações. Tem-se como principal desafio do desenvolvimento, atender às necessidades e aspirações de uma população cada vez maior.

O conceito de desenvolvimento sustentável está relacionado com um novo padrão de desenvolvimento ambiental-social, no qual ocorre uma integração permanente entre o crescimento econômico e a geração de riquezas com a preservação do meio ambiente como um todo, agregado ao direito dos indivíduos à cidadania e à qualidade de vida. O binômio meio ambiente-saúde representa a saída mais adequada para conciliar à produção de riqueza e conforto para a sociedade, sem comprometer a sobrevivência do planeta, sendo alcançado somente pela extinção de práticas predatórias.

Enfim, importa ressaltar que inserir na consciência individual uma postura de respeito à natureza $\mathrm{e}$ à sociedade se constitui em quesito sine qua non, para promoção da saúde e a qualidade de vida. 


\section{REFERÊNCIAS}

BARCIOTTE, M. L.; SACARO JÚNIOR, N. L. (org.). Sensibilização e mobilização dentro da politica nacional de resíduos sólidos: desafios e oportunidades da educação ambiental. Brasília: Ipea, 2012.

BILERT, V. S. de S. Educação ambiental como instrumento de desenvolvimento sustentável: perspectivas contemporâneas no ensino superior. C\&D-Revista Eletrônica da Fainor, Vitória da Conquista, v.7, n.1, p.73-93, jan./jun. 2014.

BRANCO, S. M. O meio ambiente em debate. 3. ed. rev. e ampl. São Paulo: Moderna, 2004. (Coleção Polêmica).

BRASIL. [Constituição (1988)]. Constituição da República Federativa do Brasil. Brasília: Centro Gráfico, 2001.

BRASIL. Ministério da Saúde. Fundação Nacional da Saúde. Termo de referência para revisão de plano municipal de saneamento básico. Brasília: Funasa, 2020.

BRÜGGER, P. Visões estreitas na educação ambiental. Ciência hoje, v. 24, n. 141, p. 62-65, ago. 1998.

CUNHA, B. P.; AUGUSTIM, S (org.) Sustentabilidade ambiental: estudos jurídicos e sociais. Caxias do Sul: Educs, 2014.

FUKS, M. Definição de agenda, debate público e problemas sociais: uma perspectiva argumentativa da dinâmica do conflito social. BIB, Rio de Janeiro, n. 49, p. 79-84, 1. sem. 2000. Disponível em: https://www.anpocs.com/index.php/bib-pt/bib-49/510-definicao-de-agenda-debate-publico-e-problemassocais-uma-perspectiva-argumentativa-da-dinamica-do-conflito-social/file. Acesso em: 20 ago. 2020.

GRÜN, M. Ética e Educação Ambiental: a conexão necessária. Campinas: Papirus, 1996. (Coleção Magistério: Formação e Trabalho Pedagógico).

LIMA, G. da C. Questão ambiental e educação: contribuições para o debate. Ambiente. soc., Campinas, n. 5, pág. 135-153, 1999. Disponível em http://www.scielo.br/scielo.php?script=sci_arttext\&pid=S1414753X1999000200010\&lng=en\&nrm=iso. Acesso em: 20 ago. 2020.

MEDEIROS, L. D.; MORAIS, P. E. Turismo e sustentabilidade ambiental: referências para o desenvolvimento de um turismo sustentável. Revista Meio

Ambiente e sustentabilidade, v. 3, n. 2, p. 198-234, 2013.

MONTIBELLER FILHO, G. O mito do desenvolvimento sustentável: meio ambiente e custos sociais no moderno sistema produtor de mercadorias. 2. ed. Florianópolis: UFSC, 2004.

MOTTA, R. S. da. Economia ambiental. Rio de Janeiro: FGV, 2006.

SHIKI, S. de F. N. Alguns elementos para o debate: desenvolvimento local sustentável. In: RUSCHEINSKY, A. (org.). Sustentabilidade: uma paixão em movimento. Porto Alegre: Sulina, 2004.

NEY, M. G.; HOFFMANN, R. Educação, concentração fundiária e desigualdade de aprendizagem no meio rural brasileiro. Rev. Econ. Sociol. Rural , Brasília, v. 47, n. 1, pág. 147-181, mar. 2009. Disponível em 
http://www.scielo.br/scielo.php?script=sci_arttext\&pid=S0103-

20032009000100006\&lng=en\&nrm=iso. Acesso em: 22 de ago. 2020.

OLIVEIRA, K. O. Pensamento Sistêmico: bases epistemológicas e paradigmáticas da construção do conhecimento nas ciências da administração. Montevidéu, p. 1-12, 2012. Disponível em: https://www.kelipereiradeoliveira.com/site/wp-

content/uploads/2018/07/basesepistemologicaseparadigmaticasdaconstrucaodoconhecimentonascienciasd aadministra88204.pdf. Acesso em: 20 ago. 2020.

PELEGRINI, S. C. A. Cultura e natureza: os desafios das práticas preservacionistas na esfera do patrimônio cultural e ambiental. Rev. Bras. Hist., São Paulo, v. 26, n. 51, pág. 115-140, jun. 2006. Disponível em http://www.scielo.br/scielo.php?script=sci_arttext\&pid=S0102-

01882006000100007\&lng=en\&nrm=iso. Acesso em: 20 ago. 2020.

SANTOS, A. M. dos; OTANI, N.; FRANZONI, A. M. B.; MELO, P. A. de. Pensamento sistêmico na educação: imprescindibilidade na era do conhecimento. In: IV CONFERÊNCIA SUL-AMERICANA EM CIÊNCIA E TECNOLOGIA APLICADA AO GOVERNO ELETRÔNICO. Anais [...]. ISBN: Português. Palmas, 2007. Florianópolis: Editora Digital Ijuris, 2007.

SILVA, Maria das Graças Miranda Ferreira. A relação das categorias pluralismo e ecletismo epistemiológico com a produção do conhecimento na história da educação. Tese (Doutorado em Educação) - Centro da Educação, Universidade Federal da Paraíba, João Pessoa, 2015.

ZILBERMAN, I. Introdução à engenharia ambiental. Canoas: ULBRA, 1997. 